\title{
"A Engenharia de Produção e a Inclusão Social: Viabilizando um Playground para Cadeirantes"
}

\author{
Daniely Rosa (Engenharia de Produção UNISAL - Brasil) \\ E-mail: rosadaniely93@gmail.com \\ Gustavo L. Torricelli (Engenharia de Produção UNISAL - Brasil) \\ E-mail: gustavolanceloti@yahoo.com.br
}

Maria F. B. P. Matias (Engenharia de Produção UNISAL - Brasil)

E-mail: mariafernanda.bragapereira@gmail.com

Marina A. Freitas (Engenharia de Produção UNISAL - Brasil)

E-mail: marina_afreitas@yahoo.com.br

Pâmela C. Silvério (Engenharia de Produção UNISAL - Brasil)

E-mail: pamelasilverios@outlook.com

Talita V. Vidal (Engenharia de Produção UNISAL - Brasil)

E-mail: talitavvidal@gmail.com

Orientador: Prof. Ms. Eugênio Benito Júnior (UNISAL - Brasil)

\begin{abstract}
Resumo - Este estudo objetiva aumentar a inclusão social de crianças cadeirantes com a instalação de brinquedos especiais produzidos com materiais de alta qualidade a um baixo custo, que se adaptem à estrutura econômica e às normas de segurança do Brasil. Atualmente, um grande problema encontrado no meio social é a não-inclusão deste público-alvo, de modo que não existem brinquedos adequados no ambiente de lazer, ou seja, playgrounds, parques de diversão, dentre outros. $O$ intuito de apresentar uma solução técnico-econômica para um balanço adaptado denominado Include é, portanto, proporcionar a sociabilização de crianças cadeirantes no lazer, possibilitando que elas compartilhem com as outras crianças as mesmas sensações e experiências.
\end{abstract}

Palavras-chave: Engenharia de Produção, Inclusão Social, Portadores de Deficiência Física.

\section{INTRODUÇÃO}

O período inicial da formação educacional de uma criança está associado ao seu primeiro contato em sociedade, participando de integração e relacionamento no qual as diferenças se ressaltam. Torna-se, assim, indispensável a inclusão social de crianças portadoras de deficiência física. Neste processo, deve-se intervir e participar ativamente para que essas diferenças não se manifestem no momento de lazer, proporcionando a todas as crianças as mesmas sensações e experiências.

Admitindo o fato de que todos somos diferentes, é preciso aceitar que de algum modo as dessemelhanças se diluem na sociedade, em que também os "mais diferentes" se perdem na multidão ou que, então, por isso mesmo são escondidos pela família [...] (FELTRIN, 2004, p. 57).

\section{INCLUSÃO SOCIAL}

O afastamento da sociedade contemporânea das propostas políticas de bem-estar proporciona situações de vulnerabilidade social que fragilizam a sociedade. [...] $\mathrm{O}$ combate às situações de vulnerabilidade é uma função essencial do Estado, sendo os programas de intervenções intitulados de inclusão social (BORBA, 17.02.2016).

A falta de conhecimento da sociedade, em geral, faz com que a deficiência seja considerada um peso ou um problema. Essa situação se intensifica, pois a falta de recursos econômicos dificulta as chances de inclusão dessas pessoas.

Nada mais verdadeiro do que afirmar que todos somos diferentes. Na natureza convive-se com a diferença. Em sociedade também. Mesmo assim, nas comunidades humanas as diferenças não são aceitas. Prefere-se viver e lidar com os iguais (FELTRIN, 2004, p.15).

Como o propósito do balanço adaptado Include é incluir socialmente crianças com deficiência física na sociedade e o lazer é um ato natural para o desenvolvimento infantil, para os cadeirantes é necessário fornecer uma solução de engenharia com um auxílio adaptado, permitindo independência na realização das atividades. As soluções genéricas de

Digital Object Identifier (DOI): http://dx.doi.org/10.18687/LACCEI2016.1.2.010 ISBN: 978-0-98228996-9-3

ISSN: 2414-6390

$14^{\text {th }}$ LACCEI International Multi-Conference for Engineering, Education, and Technology: "Engineering Innovations for Global Sustainability”, 20-22 July 2016, San José, Costa Rica. 
engenharia, por razões econômicas, têm uma componente globalizada que favorecem a exclusão. "Não há dúvidas de que existe um forte componente de exclusão na globalização e torna-se urgente identificar quais as ações que possibilitam a inclusão" (ABRANCHES et al, 2000, p.20). Essa razão pede uma atuação local mais abrangente para enfrentar essa questão.

Desse modo, faz-se necessário estruturar localmente o meio físico e social, para que crianças cadeirantes sejam capazes de utilizar brinquedos de modo independente, estabelecendo maior interação com as outras crianças e maior satisfação durante o uso do equipamento, o que favorece o desenvolvimento do livre brincar. Portanto, a inclusão social das pessoas cadeirantes significa torná-las participantes da vida social, e oferecer, aos mais necessitados, oportunidades de acesso a bens e serviços dentro de um sistema que beneficie a todos.

\section{DESENVOLVIMENTO DO INCLUDE}

O objetivo deste estudo é produzir um balanço adaptado para crianças cadeirantes com material de alta qualidade e baixo custo, que consiga ser operado por elas mesmas, possibilitando ao cadeirante o processo de entrar, acomodar-se e colocar o brinquedo em movimento sem auxílio de terceiros, viabilizando a integração com demais brinquedos em playgrounds de áreas comuns.

Ilustração 01: Design do Balanço Adaptado - Include

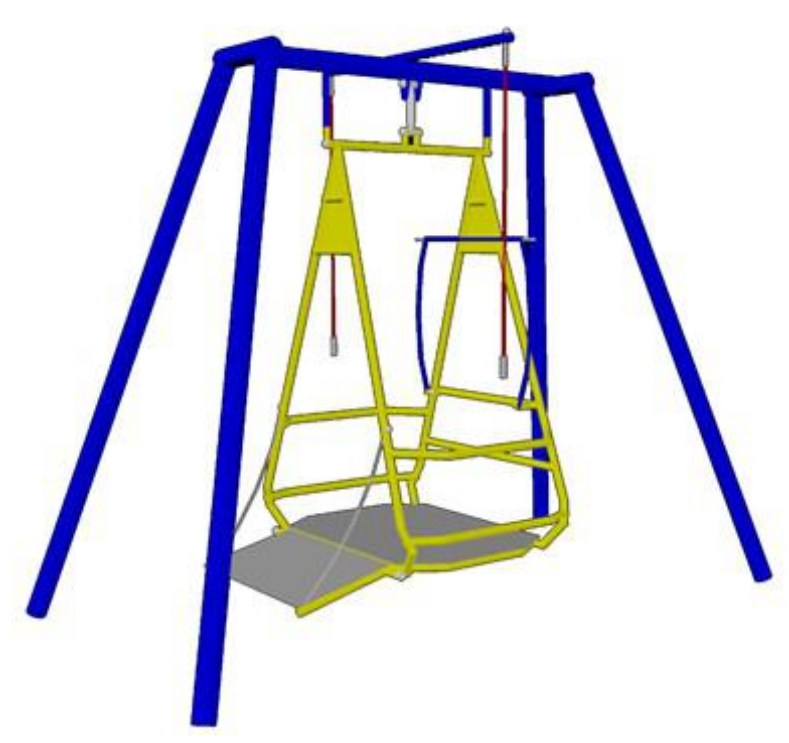

Fonte: Elaborado pelos autores

Para o desenvolvimento do balanço adaptado Include, partiu-se do princípio de promover a inclusão social de crianças cadeirantes garantindo a independência, sem negligenciar a necessidade de estruturas diferenciadas e seguras, a partir da confecção de um conjunto mecânico, utilizando componentes que não disponham de partes elétricas, motorizadas ou pneumáticas, que elevam o custo de produção e, consequentemente, o preço do produto final, de modo que todas as tomadas de decisões sejam devidamente realizadas, simuladas e testadas.

Em relação às fases do projeto do balanço, os pilares para o desenvolvimento foram: construção da ideia de um produto inovador, visar um produto de qualidade, determinar um prazo de desenvolvimento e minimizar seu custo, sempre seguindo o objetivo, realizando análises e controlando os recursos. Todos estes meios auxiliaram a criação do produto, propiciando a utilização de suas características pensadas inicialmente e até mesmo, novos atributos que surgiram com o desenvolvimento e se mostraram necessários.

As técnicas de Engenharia de Produção foram bastante relevantes para diminuir os custos do produto e aumentar sua qualidade. Foram utilizados sistemas computadorizados de projeto e simulação junto a algumas ferramentas de desenvolvimento como, por exemplo, DFMA (Design For Manufacturing and Assembly), uma "metodologia que visa a redução de custos (manufatura e montagem), aumento de qualidade do produto e produtividade de montagem através de simplificações e soluções de projeto" (FINOTTI, 20.09.2015). Geralmente essa metodologia é utilizada nas fases iniciais do projeto explorando ao máximo a eficiência dos processos, com a finalidade de obter a simplificação de etapas, trabalhando com sistematização, permitindo assim a visualização ampla sobre montagem, manuseios, dificuldades e ainda corrigir eventuais erros futuros.

Algumas etapas do planejamento e desenvolvimento do sistema de manufatura podem ser criadas, projetadas e auxiliadas por sistemas CAx (CAD, CAE e CAM), que proporcionam soluções digitais para que a administração da informação obtenha grande foco. Os sistemas CAx são definidos como:

CAD (Computer Aided Design/Drafting): Software para auxílio ao projeto, desenho, modelamento e design industrial de produtos.

CAE (Computer Aided Engineering): Software para auxílio à simulação de solicitação mecânica, força temperatura, pressão, etc.

CAM (Computer Aided Manufacturing): Software para auxílio às atividades de fabricação (SOUZA, 2009, p.36).

O sistema CAD é utilizado para projetos de desenvolvimento e design, com o objetivo de proporcionar o desenho da peça, parâmetros, medidas, fornecer informações técnicas e necessárias para a fabricação do produto. Existem sistemas CAD, para modelagem em 2D e 3D. O sistema em 2D fornece o modelamento da peça expressa em linhas e contornos e o 3D fornece o projeto em perspectiva. Os sistemas CAD possuem várias versões para atender às especificações de cada projeto. 
O sistema CAE é responsável por realizar simulações reais e servem para auxiliar o desenvolvimento do projeto. Cada etapa é testada com simulações no CAE, com objetivo de detectar resistências e fraturas no material, observando o tipo de material utilizado na confecção, a geometria, dentre outros fatores que envolvem informações relacionadas ao produto, para que as falhas sejam detectadas antes mesmo de se realizar a fabricação.

O sistema CAM é utilizado na etapa de fabricação do produto, com programas de máquinas $\mathrm{CNC}$ via software. "Calcula a trajetória da ferramenta para realizar a usinagem, além de simular a movimentação da máquina para certificação e gerar os programas CNC para a fabricação da peça" (SOUZA, 2009, p. 43).

Os softwares citados são de suma importância para verificar as condições de projetos, estruturas e métodos de fabricação. São ferramentas que auxiliam o desenho do projeto e executam alguns testes antes mesmo de o produto começar a ser fabricado.

Para o projeto do Include, com auxílio de um sistema CAD foi desenvolvido o layout cujo design elaborado contribuiu na redução de processos de fabricação e montagem e custos. Por exemplo, foi minimizado o uso de geometrias complexas para tornar o design mais objetivo, possibilitando a incorporação deste brinquedo a outros balanços em playgrounds. O sistema ainda possibilita a realização de fases de simulação de movimento, tolerância, auxilia em informações estruturais, dimensionais, propriedades físicas dentre outros aspectos, o que diminuirá o tempo de desenvolvimento por não existir a necessidade de executar todo este procedimento fisicamente, mas sim virtualmente. Após estas realizações, o projeto será encaminhado à prototipagem em escala real para realização de testes e então fazer ajustes se necessário, partindo para o processo de manufatura e produção.

\section{MATERIAL ADOTADO}

A escolha do material para a construção do balanço é essencial, de modo que se tenha um produto resistente e de alta qualidade, sem elevar o custo. A maioria dos materiais em maior ou menor grau, apresenta algum tipo de interação com o ambiente exposto. Tais interações podem comprometer as características estruturais na ductilidade e resistência do material resultando na deterioração de suas propriedades mecânicas, físicas ou de sua aparência. Nos metais este mecanismo de deterioração é dado por dissolução (corrosão), ou pela oxidação (formação de um filme não metálico).

Com um conhecimento dos tipos e uma compreensão dos mecanismos e das causas da corrosão e da degradação é possível tomar medidas para prevenir que esses fenômenos ocorram. Por exemplo, podemos alterar a natureza do ambiente, selecionar um material que seja relativamente não reativo e/ou proteger o material contra uma deterioração apreciável (CALLISTER, 2013, p. 574).

O material adotado foi o Aço Inoxidável AISI 430, composto por $17 \%$ de cromo que garante ao material elevada resistência e durabilidade protegendo-o de corrosão, dado que o brinquedo precisa resistir às intempéries e a longo período de uso. Esse aço é caracterizado como o mais apropriado em relação a custo/benefício.

\section{Ilustração 02: Aço Inoxidável AISI 430}

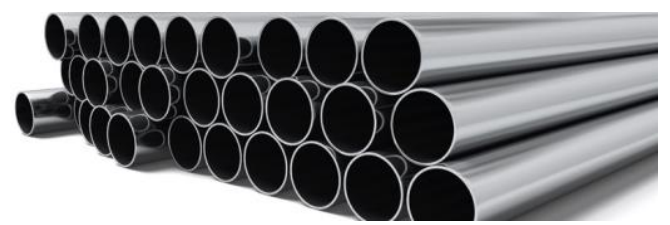

Fonte: Metais Nobres (19.02.2016)

Por definição os aços inoxidáveis são ligas de ferrocromo, substancialmente ferritas em todas as temperaturas e normalmente têm teores de cromo mais elevados do que os aços martensíticos e com menor concentração de carbono como é o caso do AISI 430, aço definido para a fabricação do balanço Include.

Os $17 \%$ de cromo caracterizam o aumento da dureza do aço pelo efeito de endurecimento por solução sólida e formação de uma camada passiva aumentando a resistência à corrosão e retardando a descarbonetação superficial. Além do cromo, o AISI 430 é composto por outros elementos conforme tabela 01:

Tabela 01: Faixa de composição química (\%) do AISI 430

\begin{tabular}{|c|c|c|c|c|c|c|}
\hline $\mathrm{C}$ & $\mathrm{Mn}$ & $\mathrm{Si}$ & $\mathrm{P}$ & $\mathrm{S}$ & $\mathrm{Cr}$ & $\mathrm{N}$ \\
\hline 0,12 máx. & 1,00 máx. & 1,00 máx. & 0,04 máx. & 0,03 máx. & $16,00 \mathrm{a} 18,00$ & 0,12 máx. \\
\hline
\end{tabular}

Fonte: Ferreira (2005, p.29)

Embora a maioria dos aços inoxidáveis seja ferríticos, alguns podem apresentar percentuais de austenitas e martensitas de acordo com a alteração na temperatura do tratamento, no caso do resfriamento a austenita pode se transformar em martensita, de forma que a estrutura bruta de forjado deste aço consistirá em uma mistura de martensita e ferrita. Diante disso um inoxidável ferrita situa-se à direita do campo austenítico no diagrama ferro-cromo, basicamente sua estrutura consiste de ferrita em todas as temperaturas, até a temperatura "líquidos" (MARTINS, 2014).

Os aços inoxidáveis ferríticos contêm de $11 \%$ a $26 \%$ de cromo, com adições de outros elementos de liga, mas frequentemente, a concentração de cromo fica entre $17 \%$ e $22 \%$. Neste caso eles teriam que ser inteiramente ferríticos,

$14^{\text {th }}$ LACCEI International Multi-Conference for Engineering, Education, and Technology: "Engineering Innovations for 
isto é, localizados totalmente no campo monofásico $\alpha$ (alfa) (ilustração 03). Aços com menos de $17 \% \mathrm{Cr}$ têm uma quantidade de austenita presente na liga dependendo da temperatura em que ela é submetida. A quantidade de austenita primeiro aumenta e depois diminui em temperaturas mais elevadas, isso acontece à medida que a liga $(\mathrm{Fe}-\mathrm{Cr})$ atravessa $\mathrm{o}$ loop da fase gama.

Ilustração 03: Diagrama de Equilíbrio de Fases Fe-Cr

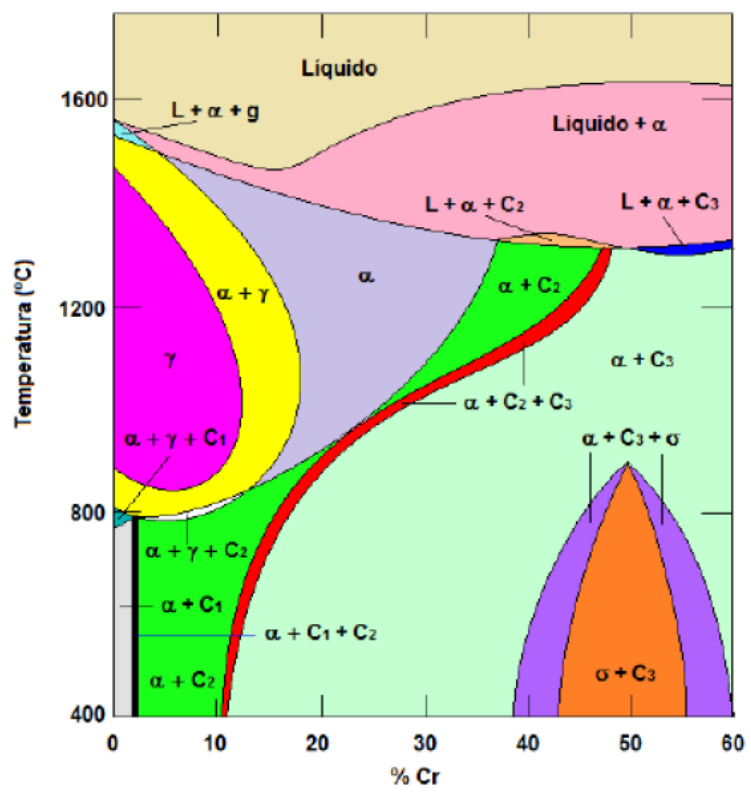

Fonte: Adaptado por Martins de Pickering (1978)

Em temperaturas acima de aproximadamente $1150^{\circ} \mathrm{C}$, sob resfriamento a austenita assiduamente precipita como uma rede nos contornos de grão de ferrita. Isso tem relevância considerável para a soldagem dessas ligas, em que alguma austenita presente na temperatura de solubilização, ainda que formada durante o resfriamento, transforma-se em martensita sob resfriamento à temperatura ambiente. A martensita pode ser revenida (tratamento térmico que tem por finalidade eliminar as tensões provocadas pelo resfriamento da têmpera e dar às peças temperadas a melhor tenacidade possível) até uma temperatura máxima de aproximadamente $780^{\circ} \mathrm{C}$, dado que acima desse limite, volta-se a formar austenita.

Os aços com $17 \%$ de cromo normalmente tornam-se completamente ferríticos e os grãos de ferritas têm uma tendência prevista para um crescimento rápido (MARTINS, 2014).

\section{SEGURANÇA DO PRODUTO}

Um dos principais requisitos a ser atendido é a segurança. Este projeto visa utilizá-la imprescindivelmente para garantir a tranquilidade na utilização do brinquedo.
No Brasil, a fabricação de produtos destinados a pessoas em cadeiras de rodas, equipamentos em ambiente urbanos e a crianças obrigatoriamente precisam estar dentro dos padrões estabelecidos pela ABNT (Associação Brasileira de Normas e Técnicas) empresa responsável pela publicação das Normas Brasileiras elaboradas pelos seus comitês.

Norma é o documento estabelecido por consenso e aprovado por um organismo reconhecido, que fornece regras, diretrizes ou características mínimas para atividades ou para seus resultados, visando à obtenção de um grau ótimo de ordenação em um dado contexto (ABNT, 16.02.2016).

A normalização é, assim, o processo de formulação e aplicação de regras para a solução ou prevenção de problemas, com a cooperação de todos os interessados. No estabelecimento dessas regras recorre-se à tecnologia como o instrumento para estabelecer, de forma objetiva e neutra, as condições que possibilitem que o produto, projeto, processo atendam às finalidades a que se destinam, sem se esquecer dos aspectos de segurança.

Assim a Norma NBR-9050 (ABNT, junho de 2004) estabelece orientações e parâmetros técnicos que diz respeito a espaços e equipamentos urbanos às condições de acessibilidade (este indicado pelo símbolo internacional de acesso inclusive a cadeirantes), visa proporcionar às pessoas mobilidade ou percepção a utilização de maneira autônoma e segura do ambiente.

\section{Ilustração 04: Símbolo de Acesso Internacional}

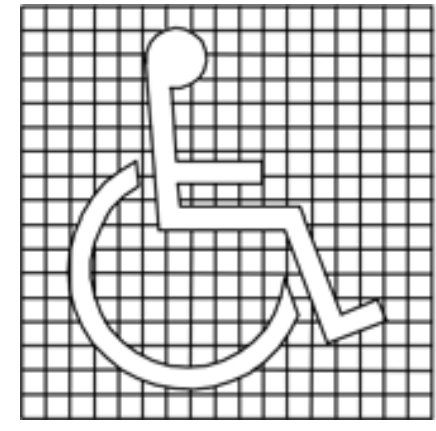

Fonte: NBR-9050 (31.05.2004)

A norma NBR-16071 (ABNT, junho de 2013) trata dos requisitos obrigatórios para os playgrounds. $\mathrm{O}$ balanço Include obedece essa norma no que se refere à qualidade da escolha do material fabricado e seu acabamento de modo a preservar a segurança do usuário. Deve ser considerada qualquer possibilidade de risco tóxico para o meio ambiente e para os usuários no caso de superfícies não revestidas, não existência de fragmentos que apresentem corrosão, cantos protuberantes e/ou pontiagudos ou qualquer posicionamento que apresente risco às crianças. 


\section{CONSIDERAÇÕES FINAIS}

A partir de uma pesquisa de público-alvo feita com dados levantados no IBGE (Instituto Brasileiro de Geografia e Estatística) foi constatada uma oferta muito pequena de produtos direcionados a deficientes físicos, em especial, brinquedos de playgrounds adaptados para suas necessidades. Diante dessa premissa foi desenvolvido o balanço Include, que além de proporcionar as sensações e a experiência propriamente do balançar, promove a independência do cadeirante, uma vez que, com o Include é possível realizar todos os procedimentos sem a ajuda de terceiros. Com estes objetivos alcançados o produto promove a inclusão social das crianças cadeirantes, e dá-lhes a oportunidade de relacionar-se socialmente, promovendo a igualdade.

Os Engenheiros devem desempenhar da melhor maneira a resolução de problemas, e não só desenvolver processos. Devem desenvolver produtos que melhoram e agregam valor à vida das pessoas. Em vista disso, o projeto do modelo foi elaborado para que seu design reduzisse os custos no processo de fabricação e montagem e possibilitasse a incorporação deste brinquedo a outros balanços em playgrounds garantindo, assim, a inclusão das crianças cadeirantes no momento de lazer, uma vez que propicia que crianças brinquem uma do lado da outra. Outro fator relevante foi a escolha do material Aço Inoxidável AISI 430 a ser utilizado, dado que o brinquedo precisa resistir às intempéries e a longos períodos de uso, garantindo durabilidade e que atenda a relação custo/benefício no país.

As técnicas desenvolvidas em Engenharia de Produção ajudaram a desenvolver um balanço adaptado e financeiramente adequado, que promova a independência, sem negligenciar a necessidade de estruturas diferenciadas e seguras, conforme as normas de segurança vigentes no Brasil, notadamente as normas NBR-9050 (ABNT, junho de 2004) e NBR-16071 (ABNT, junho de 2013). Tais técnicas auxiliam também na tomada de decisões estruturais, prototipagem e na escolha do processo produtivo mais adequado.

\section{REFERÊNCIAS}

[1] ABNT, Associação Brasileira de Normas e Técnicas. Normalização Definição. Disponível em: <http://www.abnt.org.br/normalizacao/o-quee/o-que-e> Acesso em: 16 de fevereiro de 2016.

[2] ABNT - NBR 9050 - Acessibilidade a edificações, mobiliários, espaços e equipamentos urbanos - Rio de Janeiro - RJ. 30 de junho de 2004.

[3] ABNT - NBR 16071 - Playgrounds - Rio de Janeiro - RJ. 16 de junho de 2013.

[4] ABRANCHES, Cristina et al. Inclusão dá Trabalho. Belo Horizonte. Editora Armazém de Ideias, 2000.

[5] BORBA, Andreilcy Alvino; LIMA, Herlander Mata. Exclusão e inclusão social nas sociedades modernas: um olhar sobre a situação em Portugal e na União Europeia. Disponível em:

<http://www.scielo.br/pdf/sssoc/n106/n106a03.pdf> Acesso em: 17 de fevereiro de 2016.

[6] CALLISTER, Willian D. Ciência e engenharia de materiais: uma introdução. Rio de Janeiro. Editora LTC, 2013.
[7] FELTRIN, Antonio Efro. Inclusão Social na Escola: Quando a pedagogia se encontra com a diferença. São Paulo. Editora Paulinas, 2004.

[8] FERREIRA; J. S. Efeito da fração volumétrica de martensita, formada no resfriamento após recozimento intercrítico, no grau de estriamento, propriedades mecânicas e estampabilidade de um aço tipo AISI 430. Dissertação de Mestrado. Universidade Federal de Minas Gerais, 2005.

[9] FINOTTI, Maurício Bombonato et al. DFMA em Ação: a metodologia aplicada no desenvolvimento de uma secadora centrífuga. Disponível em: <http://www.abcm.org.br/app/webroot/anais/cobem/1999/pdf/aacfhe.pdf $>$ Acesso em: 20 de setembro de 2015.

[10] MARTINS, Marcelo. Aços Inoxidáveis. Material de aula: Ciência dos Materiais II. Americana - SP, disponibilizado em: 28 de agosto de 2015.

[11] METAIS NOBRES, Metais não ferrosos - Aço Inoxidável. Disponível em: <http://www.metaisnobres.net/produtos> Acesso em: 19 de fevereiro de 2016.

[12] SOUZA, Adriano Fagali de et al. Engenharia integrada por computador e sistemas: CAD/CAM/CNC - princípios e aplicações. São Paulo. Editora Artliber, 2009.

14 ${ }^{\text {th }}$ LACCEI International Multi-Conference for Engineering, Education, and Technology: "Engineering Innovations for 